\title{
Philosophy's Undergraduate Gender Gaps AND EARLy INTERVENTIONS
}

\author{
ADAM PIOVARCHY \\ The University of Sydney
}

\begin{abstract}
Researchers have found that philosophy's gender gap gradually increases as students progress from first year to majoring and into graduate school. By analysing enrolments in philosophy units at Australian universities from 2005 to 2017, I argue that early interventions are likely to be more effective than typically assumed. My findings are consistent with previous data but improve on previous analyses in a few ways. First, this paper quantifies women's risk of leaving philosophy relative to men at each point throughout their studies and confirms women's relative risk of leaving philosophy is much higher than men's throughout all of their undergraduate studies. Second, this paper shows there is a large pool of women who leave philosophy after taking only one unit and argues studies or interventions which focus on students closer to graduating may miss this group of women. Third, this paper argues interventions aimed at this group of women could be more effective at reducing our discipline's gender gap than later interventions, because a much lower rate of uptake is needed. Trials aimed at identifying effective interventions may also be easier to conduct than we typically assume. I also identify four kinds of interventions that are worth trying, based on evidence from studies on gender gaps in STEM fields. These include having more role models for female students, exposing girls to philosophy from a younger age, boosting female students' sense of belonging, and expanding the scope of careers that we market to students as possible with a philosophy major.
\end{abstract}

\section{Philosophy's Gender Gaps}

It is well known that philosophy has large gender gaps at a number of levels. Women make up 19-26\% of philosophy faculty (Beebee \& Saul 2011; Goddard et al. 2008; Haslanger 2008; Norlock 2006; 2011; Paxton, Figdor, \& Tiberius 2012; Van Camp 2010), 27-36\% of graduate students (Goddard et al. 2008; Paxton 2013; Paxton et al. 2012; Schwitzgebel 2016; Solomon \& Clarke 2009), and author

Contact: Adam Piovarchy <adam.piovarchy@sydney.edu.au> 
only $12-16 \%$ of publications accepted to top journals (Haslanger 2008; Wilhelm, Conklin, \& Hassoun 2017). These gaps don't seem to be an effect of academic careers in general. In 2015, women made up $46 \%$ of overall US PhD completions, and $57 \%$ of US PhD completions in non-STEM (science, technology, engineering and mathematics) fields (National Science Foundation, National Center for Science and Engineering Statistics, Directorate for Social, Behavioral and Economic Sciences 2017).

There are three main approaches to understanding the causes of these gaps and the way they develop. Much of the philosophical literature centres on experience-informed explanations of why women may leave the discipline at a higher rate than men, citing numerous examples of discrimination. Sometimes these explanations are supported by psychological studies demonstrating that certain variables are correlated with women's perception by others, interest in a task or representation in certain domains. These philosophers then argue such variables are present for women in philosophy and infer these variables could be having similar effects, creating gender gaps.

For example, Valian (2005) and Haslanger (2008) argue gender schemas are the cause of gender gaps in many professions. Their evidence includes studies showing that men are more likely to be picked as the leader of the group by strangers, that women are rated less favourably than men when they are assertive, are perceived as being shorter than they are, and that men and women receive different ratings for identical CVs and term papers, amongst other things. These small differences could add up over time, leading men to gain an "accumulation of advantage" (Valian 2005: 204) ${ }^{1}$

Antony (2012) has argued women's lack of representation in philosophy may be due to interaction effects between certain features of philosophy's academic environment, leading to a 'perfect storm' of factors which intensify each other. These interaction effects not only lead to gender gaps larger than those found in other disciplines, they make it difficult to identify the underlying factors. For example, if philosophers' unconscious biases were no greater than those of members from other disciplines, one might conclude that unconscious bias does not contribute to philosophy's gender gap. But Antony argues there may be more opportunities for bias to be triggered in philosophers since there are more discussions regarding formal reasoning than in other disciplines, and more opportunities to interpret a novel question as simply confused. Women philosophers also often have to choose between following philosophical norms or feminine

1. Dodds \& Goddard (2013) also argue that gender stereotyping, sexism, the way philosophy is taught, undervaluing of feminist philosophy, and gender schemas all contribute to gender gaps. Friedman (2013) argues that philosophy's gender gaps could be caused by discrimination in hiring, firing, and salary practices, and women being alienated by the adversarial style of philosophers or ways in which philosophy is taught. 
norms, such as when choosing whether to raise an objection (which risks seeming rude) or remaining silent (which risks being dismissed intellectually).

The second method is to survey philosophy students directly and see if there are any differences between male and female students (e.g., interest in philosophy, identification with philosophy, or intention to major). These studies then infer such differences could be causing those gaps to develop, with the next step being to figure out what causes those differences. For example, Calhoun (2009) found that the proportions of men and women who intended to major at Colby College in first semester very closely matched the proportions who actually majored. ${ }^{2}$ Dougherty, Baron, and Miller also found through surveys of first year students that women had "reduced interest, reduced confidence, reduced ability to self-conceive as philosophers, and reduced comfort in class [and these] all predicted one another" (2015b: 469), which suggests schemas are operating. Students' attitudes did not change over the duration of the unit. This indicates the schema was largely the product of factors encountered before entering the classroom, and that students' classroom experience did not exacerbate these schemas. ${ }^{3}$

The third method is to directly change certain factors and observe whether this has any effect. Whilst many philosophers have proposed plausible explanations and remedies (e.g., adding more women philosophers to syllabi to help disrupt gendered schemas), few of these interventions have been tested. 4 This is unfortunate, because after looking at how our discipline's gender gaps change throughout the undergraduate-to-professor pipeline, I believe that assessing the efficacy of particular interventions may be easier than previously assumed. I also believe that remedies targeted towards women taking (or yet to take) their very first philosophy course are more likely to succeed than other measures that have been proposed.

2. Calhoun argues this may be because women find it "harder to imagine themselves as philosophy majors, or at least suspect that being a philosopher and being female is a less pleasant, or less promising, option than other academic options" (2009: 218). Their schemas may then cause them to read certain things (e.g., chilly climates, sexist encounters, male heavy syllabi) as normatively representative of philosophy and its relation to women. Her solution is to degender philosophy by using more images of female philosophers, using more texts by women, and making degendering plans a long term-project for departments.

3. Similar results were found by Thompson, Adleberg, Sims, \& Nahmias (2016). Their survey showed female students had less identification with philosophy, less of a sense of belonging, and were more likely to believe that success in philosophy required brilliance rather than hard work. Dobbs (2017) also found that much fewer women intended to major in philosophy than men before beginning university..

4. An exception to this is Thompson et al. (2016). They found that giving a ten-minute talk on the career benefits of a philosophy degree to students in an introductory unit, and increasing the proportion of women on syllabi from $10 \%$ to $20-30 \%$ did not have any effect on female students' willingness to continue studying philosophy. 
This paper has two aims. The first aim is to identify how philosophy's undergraduate gender gap develops over time, in order to identify when interventions to reduce this gap could be most effective. In the first half of this paper, I look at undergraduate philosophy enrolment data from Australian universities between 2005 and 2017. Some researchers have discovered a drop in female representation occurs between first year and majoring, but more precise information about how this gap develops is currently lacking. My analysis builds on these studies to provide a more accurate understanding of how this gap arises. Specifically, this data shows there is a large pool of women who are interested enough to start studying philosophy, but who leave after taking only one or two units. This pool of women could be a resource in achieving gender parity, because interventions targeting these students require only small rates of uptake to have large effects on later gender gaps.

In the second half of this paper, I investigate which interventions are likely to be effective. This is by considering the literature on interventions to reduce gender gaps in STEM fields. Although Dougherty, Baron and Miller's (2015a) survey looks at some studies from STEM fields, they were largely concerned with identifying causes of philosophy's gender gap, rather than remedies. As a result, they conclude "we have little empirical evidence that indicates which interventions may increase female students' propensity to major in philosophy [or] which interventions are the most effective at ameliorating any of the effects [causing women to leave philosophy]" (2015a: 24). After looking into studies from STEM fields, I believe four kinds of interventions could reduce philosophy's gender gaps. These include having more role models for female students, exposing girls to philosophy from a younger age, boosting female students' sense of belonging, and expanding the scope of careers that we market to students as achievable with a philosophy major.

\section{Australian Degree Structures}

Australian undergraduate Arts degrees and pathways into graduate studies differ from those commonly found in other Anglophone universities. Bachelor of Arts students usually take three years to complete their undergraduate coursework. Students with high marks who are interested in research then have the option of enrolling in an honours year, which usually consists of four units, and a 10,000-15,000 word thesis. The honours component of undergraduate degrees is intended as a shorter pathway into $\mathrm{PhD}$ candidature, in place of completing a master's degree. Some students will complete honours, and then go on to complete a master's degree. Although I was unable to obtain direct data on the numbers of students who majored in philosophy, nearly all Australian universi- 
ties require eight units of study to be completed to major. I thus considered any student who completed eight units to have majored in philosophy. ${ }^{5}$

\section{Data Sample}

The data presented here comes from two requests made to the Australian Government's Department of Education. The first request regarded undergraduate enrolments. This data was limited to domestic students who completed a Bachelor of Arts, Bachelor of Philosophy or Bachelor of Liberal Studies (including honours degrees and double degrees) at Australian institutions between 2008 and $2017 .{ }^{6}$ This was to exclude the large numbers of students from other degrees who take philosophy units as electives, but never intend to major. This dataset does include Bachelor of Arts students majoring in other fields who may also never have intended to major in philosophy. However, Bachelor of Arts students are generally not required to declare a major until their final year and have a large number of elective units. This means it is quite easy for students whose interest is piqued by philosophy to study it while initially intending to complete a different major. It also means there is a relatively low opportunity cost to enrolling in philosophy units. By contrast, students in (say) science degrees may only have one or two electives in their normal degree structure. This means that taking additional philosophy courses would require extending the length of one's studies, switching degrees, or taking on a higher-than-full-time study load. I thus considered Bachelor of Arts, Bachelor of Liberal Studies and Bachelor of Philosophy students to be the primary group we are interested in when looking at philosophy's missing women.

Institutions which did not have data available on the number of undergraduate units taken were excluded for this first request but included in the second. The second request looked at the total numbers of domestic students commencing and completing master's and PhD research degrees in philosophy from 2005-2017 at all Australian tertiary institutions for which data was available. I originally intended to gather figures on which students from the first request went into research degrees in a retrospective cohort study. This turned out not to be possible due to data on unit enrolments not being collected prior to 2005, and the small number of philosophy students who both began their studies and

5. Most degree structures also make it difficult to have studied eight units without having thereby majored, and it seems likely that students motivated enough to complete eight units would ensure they completed a combination of units sufficient for majoring

6. Our ethics board advised that formal ethics approval was not needed as this data was tokenized before being accessed. Requested data, details, and list of included institutions are available through the Open Science Foundation at: https://osf.io/bncq5. 
completed a doctorate during this period. Examining the number of students who commenced or completed a research degree at all universities allowed for a more representative sample.

\section{Findings}

\subsection{Relative Gender Gaps}

The overall undergraduate philosophy gender distribution was almost at parity, with female students making up $52.2 \%$ of total enrolments across the twelveyear period. Overall female gender distribution for total enrolments varied somewhat between universities $(S D=6 \%$ ), ranging from $64 \%$ at Charles Sturt University to $44 \%$ at The University of Melbourne.

Focusing on enrolments alone can be somewhat misleading, as the above figures do not distinguish between (say) one student taking four units and four students each taking one unit. The averages also hide the large variation within universities, because introductory units generally have much higher enrolments than third-year units.

This data shows $60 \%$ of individual students who took at least one philosophy unit were female. This is slightly higher than what would be expected given female students make up 55\% of university students at Australian universities overall (Australian Government 2015). However, male students were more likely to take more philosophy units. This accounts for why the average class is $52.2 \%$ female, despite there being more individual female students taking at least one philosophy unit.

Figure 1 shows the proportion of students who were female at each stage of study. After a strong decrease between students' first unit and majoring, and majoring and honours, there was an increase between honours and commencing a master's degree or $\mathrm{PhD}$, followed by a slight decrease between commencement and completion of a postgraduate research degree. There is a clear overall trend where the gender gap widens as the number of units taken increases. This trend is what we would expect to observe based on previous research showing a widening gender gap as women progress through their studies.

The dotted line marks that the undergraduate and HDR figures come from two separate data requests. A number of factors could explain the observed increase in women's representation between honours and commencing a research degree. For example, many ambitious honours students go on to complete research degrees in other countries, and their continuation would not be recorded here. Likewise, some HDR students included in this sample will have completed 


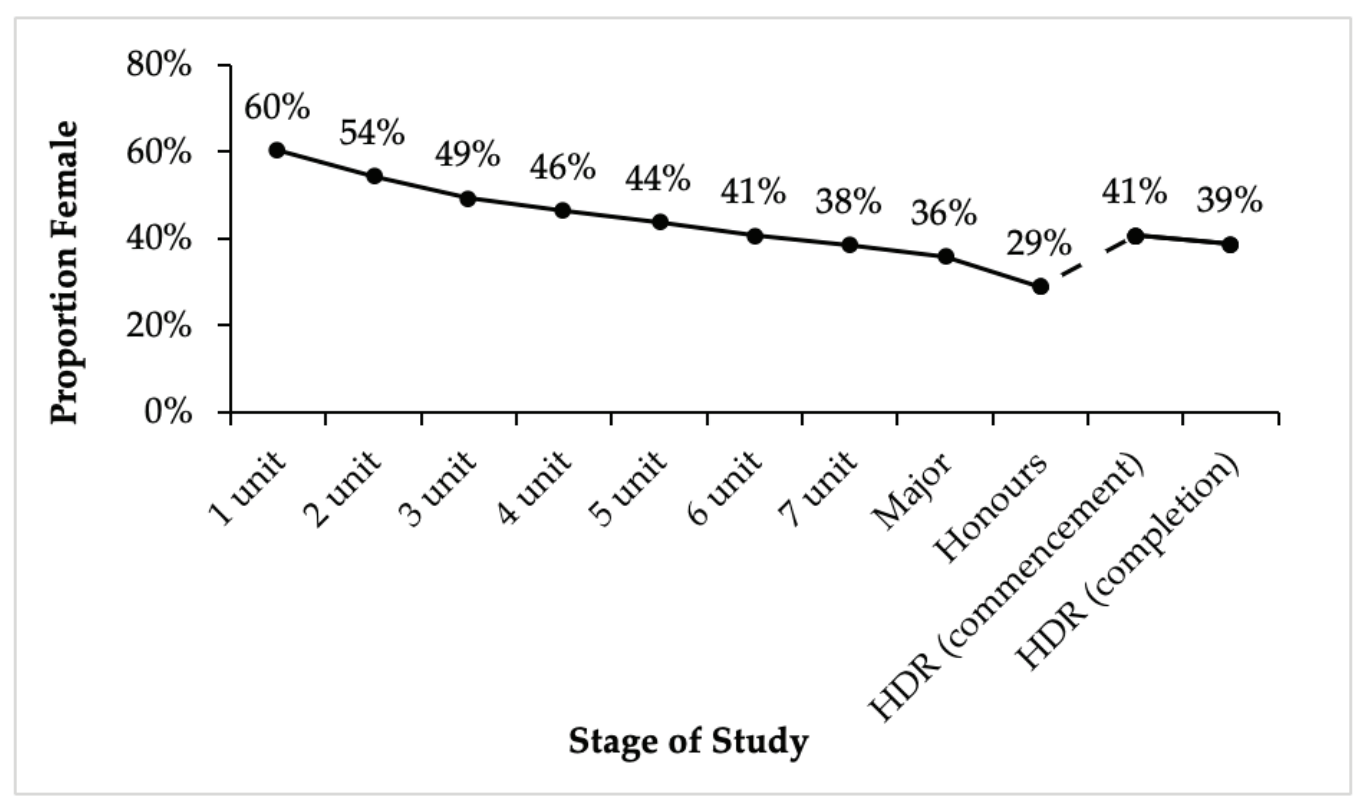

Figure 1. Proportion of students at each stage of study who were female.

their undergraduate studies in other countries. The HDR (commencement) figure would also include students who majored in philosophy without taking honours, but then decided to begin a master's degree some years later. It would also include students who began a philosophy research degree without having first completed a Bachelor of Arts, Bachelor of Liberal Studies or Bachelor of Philosophy.

Figure 2 plots a survival analysis of the two undergraduate populations, showing what proportion of male and female students 'survive' (i.e., continue) into the next stage of studying philosophy. The gap between the red and blue lines shows the difference between our observed numbers and what we'd expect if sex had no relationship to when students stopped studying philosophy. The size of the gap between the red and blue lines allows us to see how many female students are 'missing' at each point and how the gap changes over time.

Table 1 presents the odds that female students will stop studying philosophy compared to male students at each point in their studies. A ratio of 1.0 means female and male students are equally likely to stop studying at this point. A ratio above 1.0 means female students are more likely to stop studying at this point than male students. The chi-square column is a measure of how much the observed numbers of students who completed (n) units deviates from what we'd expect if gender had no relationship to continuation rates at each point of study, given the number of students who completed (n - 1) units. The $p$-value column says how statistically significant this deviation is. 


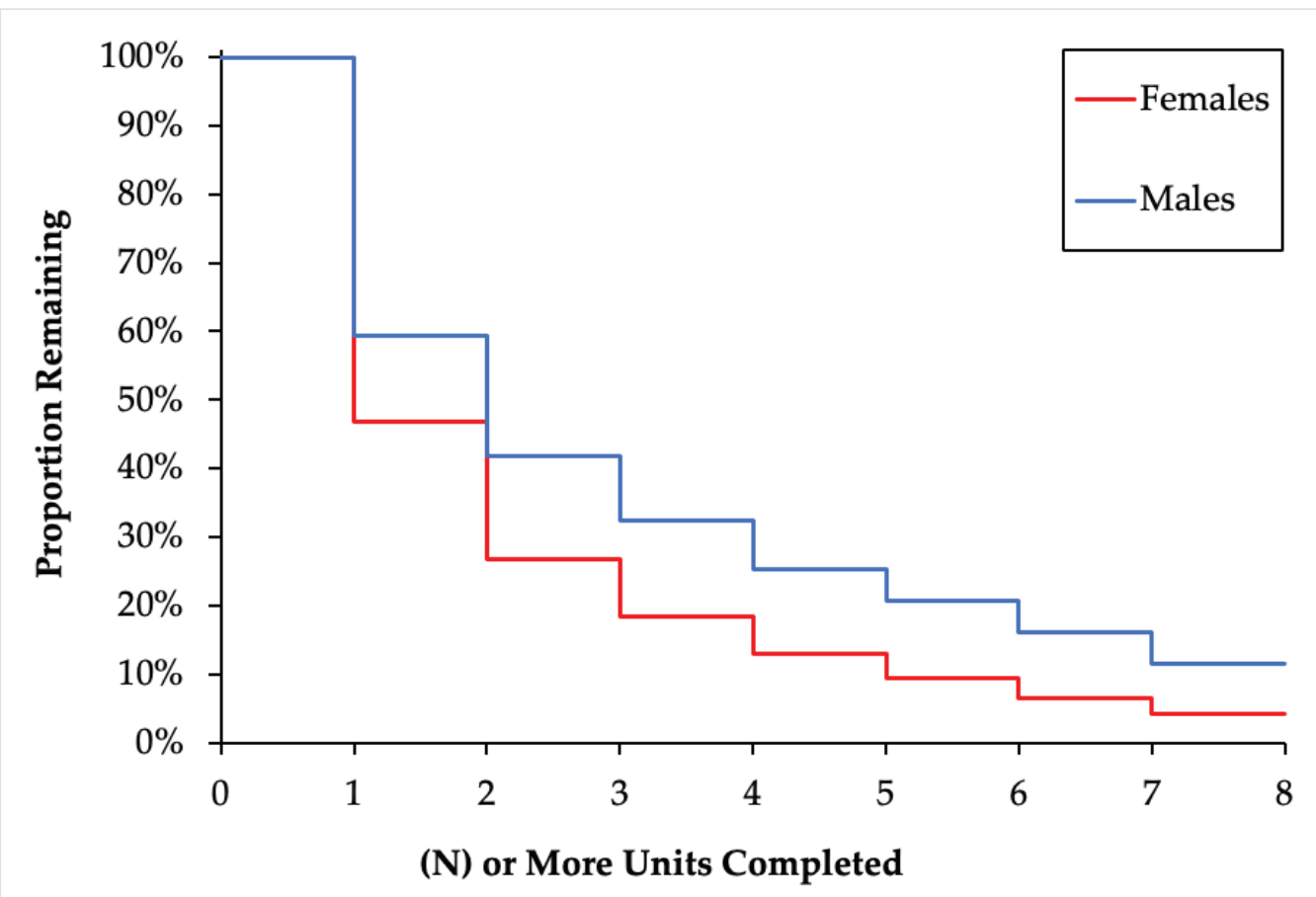

Figure 2. Proportion of starting students who completed (n) or more units, by sex.

Table 1. Odds ratio of female students leaving philosophy compared to male students at various stages of study.*

\begin{tabular}{lccccc}
\hline & & & & 35 Confidence Interval \\
\hline Time Period & $\begin{array}{c}\text { Odds Ratio } \\
(\mathrm{F} / \mathrm{M})\end{array}$ & $\begin{array}{c}\text { Chi Square } \\
(\chi 2)\end{array}$ & $\begin{array}{c}\text { P-Value } \\
\text { Bound }\end{array}$ & $\begin{array}{c}\text { Upper } \\
\text { Bound }\end{array}$ \\
\hline 1-2 units & 1.6684 & 406.9666 & $<0.0001^{*}$ & 1.5872 & 1.7538 \\
3-3 units & 1.7833 & 256.2326 & $<0.0001^{*}$ & 1.6608 & 1.9147 \\
4-5 units & 1.5198 & 73.2625 & $<0.0001^{*}$ & 1.3805 & 1.673 \\
5-6 units & 1.5330 & 54.6726 & $<0.0001^{*}$ & 1.3684 & 1.7175 \\
6-7 units & 1.6656 & 53.9178 & $<0.0001^{*}$ & 1.4525 & 1.9099 \\
7-8 units (Major $)$ & 1.5149 & 29.4997 & $<0.0001^{*}$ & 1.3034 & 1.7607 \\
Major-Honours & 1.4138 & 17.1533 & $<0.0001^{*}$ & 1.1997 & 1.6661 \\
1 unit-Major & 1.4733 & 10.166 & $0.0015^{*}$ & 1.16 & 1.8711 \\
HDR Commencement - HDR & 2.963 & 506.518 & $<0.0001^{*}$ & 2.6854 & 3.2693 \\
Completion & 1.2167 & 1.9755 & 0.1601 & 0.9254 & 1.5998 \\
\hline
\end{tabular}

${ }^{*}$ Alpha $=0.005$ due to Bonferroni correction for multiple comparisons. ${ }^{*}$ denotes statistically significant result. 
At every point the odds ratio is above one, indicating female students were at a higher risk of leaving philosophy than male students at every point in the undergraduate pipeline. This risk decreased slightly as female students progress through their studies. Overall, female students who took at least one philosophy unit were 2.963 times more likely to stop studying philosophy than male students who took at least one philosophy unit. Female students who majored were also less likely to enrol in honours than male students who majored.

Unfortunately, I was not able to assess the odds ratio of female honours students going on to commence higher degree research compared to male honours students, due to these figures coming from separate requests. 7 Whilst female students who began a postgraduate research degree in philosophy appear slightly less likely to complete their degree than male students who began a postgraduate research degree in philosophy, this difference was not statistically significant $(p=0.1601 ; 95 \% C I=0.9254,1.5998)$.

This leads me to the first two contributions of this paper. First, it is worthwhile having a quantifiable representation of how women's risk of leaving undergraduate philosophy changes over time. Second, this data shows that women are consistently at greater risk of leaving philosophy than men throughout their entire undergraduate studies.

\subsection{Absolute Gender Gaps}

When trying to describe what relationship exists between a variable (e.g., gender) and some outcome (e.g., studying philosophy) it is customary to focus on relative differences, or differences in rates between groups. This is because different sample sizes can make it appear that one group is behaving differently. For example, if Restaurantı has 20\% fewer complaints than Restaurant2, but Restaurant2 serves six times as many patrons, we need to look at the rates of complaints rather than number of complaints in order to identify that customers are more likely to complain at Restaurant1. This is what Figures $1-2$ and Table 1 do.

However, when thinking about interventions and trying to predict what effects a proposed remedy will have on a population, it can be useful to look at the absolute size of populations instead of rates alone. To use our restaurant example, if we wanted to decrease the amount of complaints amongst patrons overall but could only intervene once, looking at the actual numbers of patrons allows us to see it may be more effective to intervene in Restaurant2 even though people are less likely to complain there.

To apply this reasoning to our case at hand, I believe graphs emphasising

7. The number of PhD commencements was larger than the number of honours completions. Using these numbers would treat the relative risk of dropping out as negative, making an odds ratio comparison not possible. 


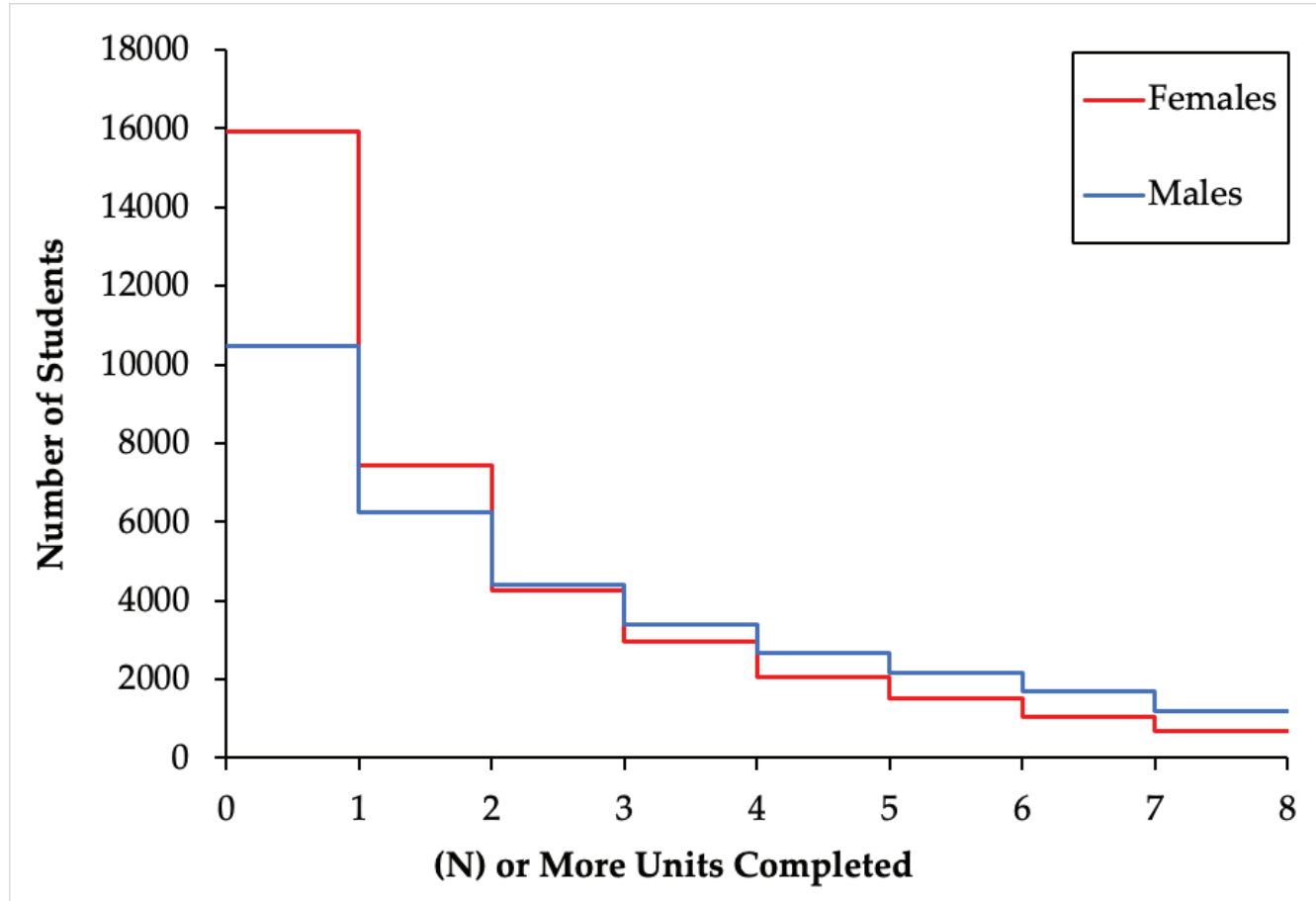

Figure 3. Number of students who took (n) or more units, by sex.

overall trend lines (such as Figure 1) miss something important, particularly when we are trying to identify which remedies will reduce philosophy's gender gap. They neglect to show the absolute difference in enrolments between male and female students. To show what I mean, consider the survival analysis in Figure 3 which shows the absolute number of students who took (n) number of units in our sample.

Figure 3 clearly shows that the pool of female students who took at least one philosophy unit is much larger than the pool of male students who took at least one philosophy unit. Whilst it is true that the relative gap between male and female students grew larger as the number of units increased, the absolute size of the gap (the space between the red and blue lines) did not change greatly as the number of units taken increased.

The size of the gender gap (understood as deviation from parity, rather than deviation from expected proportion) over time can be represented another way. Figure 4 shows the absolute size of the female gender gap for each group of students who took (n) or more units.

Some things are worth noting about this figure. The first is the relative surplus of female students compared to male students at the left of the graph. When 


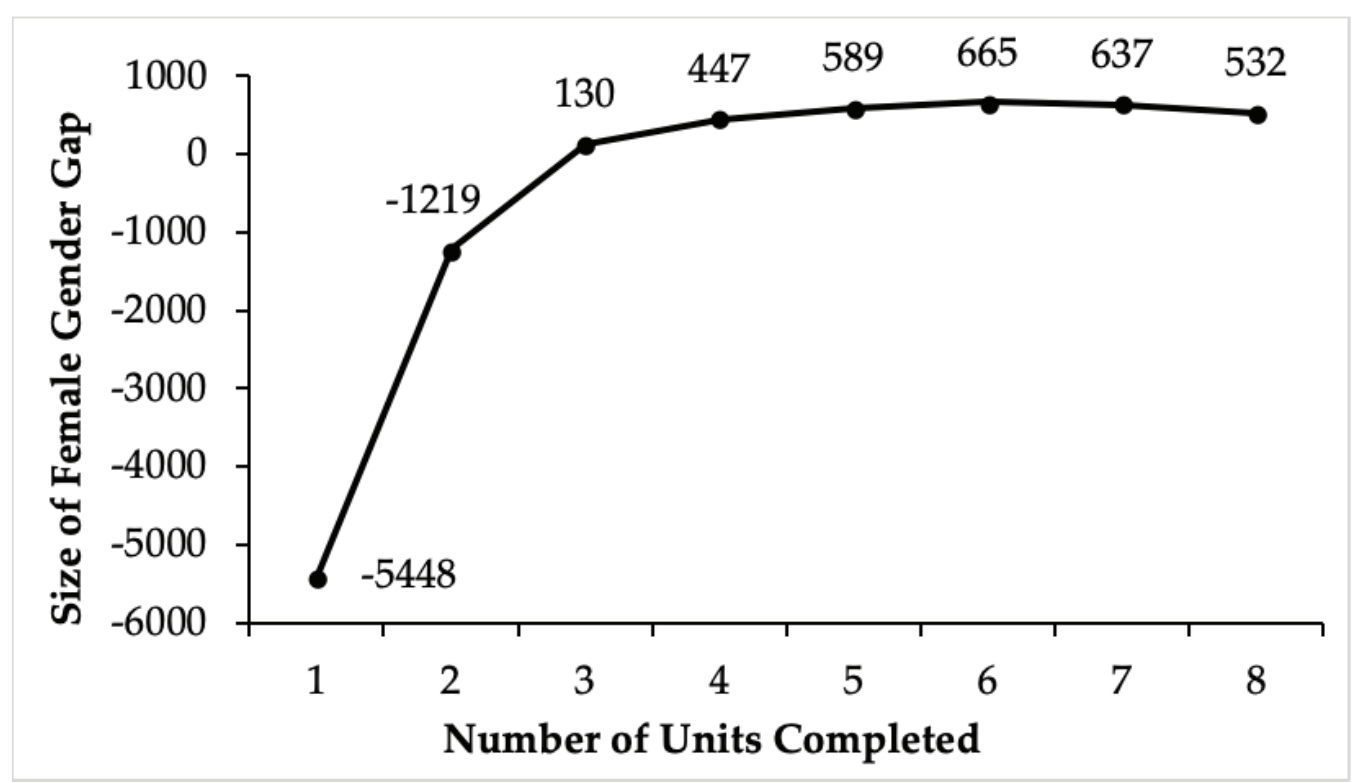

Figure 4. Absolute size of gender gap by number of units taken.

looking at the number of students who enrolled in at least one philosophy unit, there were $47 \%$ more female students than male students. ${ }^{8}$ When looking at the number of students who went on to take a third unit however, female students were down to a $3 \%$ relative deficit. This is a very sharp drop, and a large 'leak' in our discipline's pipeline which I believe has not been noticed by many philosophers or adequately emphasised in the current literature. 9 This figure also tells us how many female students our sample was 'missing' from achieving parity at each point in time, when more female students left than male students, and how many female students left at those points.

\section{Generalizability of Data}

In this dataset, the proportion of females amongst students who complete at least one unit was $60 \%$, which was slightly above the Australian first year aver-

8. As noted earlier, part of this gap is due to the fact that women make up $55 \%$ of students studying at university generally, and $60 \%$ of students taking introductory units. If we expected female students to not take a second unit at the same rate as male students, we would expect the second data point in Figure 4 to read -2019. I leave it open what figure should be our goal, and whether $50 \%$ or $\sim 60 \%$ should be our baseline from which to assess whether there are gaps that ought to be remedied.

9. Paxton et al. (2012) identify "a significant drop" occurs between introductory units and majoring, but don't specify if this drop mostly occurs after only taking one unit. 
age of $57 \%$ reported by Goddard et al. (2008) for Australian universities between 2001 and 2006. Similarly, the UK Higher Education Statistics Authority (2017) report that women made up 55\% of UK first year students enrolled in Historical and Philosophical Studies in 2015, and Thompson et al. (2016) report their introductory philosophy unit is $55 \%$ female. This seems like good evidence our data on students who are just beginning their studies is representative of other institutions.

Women made up $36 \%$ of philosophy majors in this dataset. This figure is slightly higher than the proportion of majors in the USA (30-35\%) (Paxton et al. 2012; Thompson 2017), but somewhat lower than in the UK (46\%) (Beebee \& Saul 2011). This suggests there is some difference between countries regarding the proportion of women who major in philosophy, but the overall trend line appears quite similar. The finding that women made up $41 \%$ of commencing graduate students is above previous research finding that women make up 27$36 \%$ of graduate students in the US and the UK (Beebee \& Saul 2011; Paxton 2013; Paxton et al. 2012; Schwitzgebel 2016; Solomon \& Clarke 2009).

As always, however, there may be some issues with the generalizability of this data. Australian university degree structures differ to those in other countries. First, students enrolled in a Bachelor of Arts, Liberal Studies, or Philosophy have a lot of freedom to study units from multiple subject areas. Even if students have a firm idea that they would like to major in something other than philosophy, they have many elective units and therefore a relatively cost-free opportunity to try studying philosophy. Additionally, costs of tuition are much lower than those in other countries such as the US, and our government gives students interest-free loans. It is therefore much less prohibitive to study subjects which may not be perceived to contribute to one's career prospects, and failing a unit one is not confident in studying carries a much lower risk of penalty. These factors could mean that undergraduate gender gaps develop differently in other countries, or that interventions which are effective in Australian institutions may not be effective in others.

\section{Two Kinds of Approaches}

Earlier I noted that few philosophers have directly assessed whether certain interventions are effective in reducing our discipline's gender gaps. This may be partly because some proposed explanatory factors for philosophy's gender gaps are inherently difficult to measure (e.g., clashes between schemas). But it could also be because assessing the effects that certain factors have on women's representation, or attempting to mitigate their negative influence, is thought to only be possible by observing a cohort of students for many years. 
I believe the large number of women who leave philosophy after taking one unit are a potential resource for helping close the major-level gender gap. I have presented Figures 3 and 4 because they suggest certain approaches may be more effective than we typically assume. Focusing on these women can seem difficult because it involves a large pool of students, most of whom will not major regardless of gender, and there is no way to identify which women could be convinced to major if slight changes were made. But having a large pool of students to work with means only a low conversion rate is needed to close the gap. When looking at the total pool of female students who take at least one philosophy unit but do not major, if only an extra 3.5\% had been convinced to major, the eight-unit major gap in Figure 4 would be eliminated. If an extra $4.6 \%$ of female students who took at least one unit without majoring could be convinced to major, the female gender gap would disappear at every stage in Figure 4, and we would have more women majoring than men. These figures seem like quantifiable, understandable and achievable goals, against which specific remedies can be assessed.

Against this proposal, someone might reply that it is easier or more effective to focus on women who are close to majoring and may be considering graduate research degrees. This approach initially seems appealing, because it focuses on women who have already completed philosophical training, who treat enrolling in graduate school as more of a live option than women just beginning their studies. This group of women is also relatively small compared to the total number of students who enrol in undergraduate philosophy units, making them easier to directly contact and communicate with.

What may not be noticed is that attempting to achieve gender parity and eliminate the major-level (eight unit) gender gap (532 students) in Figure 4 by focusing on women who are close to majoring would require very high uptake. For example, of the 1493 female students who completed six units, 663 went on to major in philosophy and 830 chose not to major in philosophy. Closing the major gap by encouraging more of these students to continue would thus have required convincing 532 of these 830 female students to major. This is a $64 \%$ conversion rate. Remedies that primarily target women who have already taken some philosophy units and are familiar to teaching staff may thus require much higher success rates than at first glance.

Of course, the aim is not to achieve $50 \%$ representation for the sake of having $50 \%$ representation. Rather, the existence of a gender gap is taken to be evidence that certain factors are having certain negative effects on women, for example, by making women feel less welcome in philosophy, or causing them to see being a philosopher as less of a live option. The goal in aiming for 50\% representation is to have our discipline arranged in such a way that women do not experience extra pressures to leave or face extra obstacles to remaining in philosophy. Trying to bolster the number of women in philosophy by encouraging more female 
students in introductory units to continue may seem to avoid engaging in this project. Instead of removing barriers for women who would have otherwise continued in our discipline, this approach may appear to 'supplement' the missing women with extra women who otherwise would not have continued studying philosophy for more benign reasons. Mackenzie and Townley rightly warn that obsessing with measures of equity alone "risks becoming an 'add women and stir' approach" (2013: 164).

I think approaches which focus on students in introductory units shouldn't be discounted for a few reasons. First, and most importantly, it seems this approach could ameliorate many factors that plausibly contribute to the gender gap and do so in the right way. Simply having more women majoring in philosophy is likely to reduce students' stereotypes about what the average philosophy student is like, mitigate the effects of a 'chilly climate' in classrooms, and create more opportunities for meeting people with similar interests and making friends. These things are likely to in turn reduce the strength of the philosopher = man schema (or lead to new schemas) and create feedback loops, making it easier for women to see themselves as professional philosophers.

Second, discipline-wide interventions aimed at current philosophers and localised interventions which target new students are not mutually exclusive. It is possible to do both, and it would be a mistake to think encouraging firstyear students to major somehow comes at the expense of broader, disciplinewide remedies. Many people who want to improve women's participation in philosophy may have the ability to try interventions focused on introductory undergraduate students at their institution but lack the power to try other kinds of measures. It seems worthwhile to make these people aware that interventions targeted at students in introductory units require little uptake to have big effects.

Third, it has been argued there are various other moral and epistemic reasons to have more women in philosophy. These include improving professional confidence of women faculty, improving others' standing and regard for women philosophers, improving philosophical methods and topics (Friedman 2013), and creating more diverse kinds of philosophy (Weinberg 2018). Improving the number of women by focusing on this approach still helps achieve these goals.

Noticing this large initial drop has implications for future research. Tracking students who are close to majoring and seeing if any interventions have lasting effects presents a number of challenges. Students often change institutions when moving into postgraduate research, the postgraduate and faculty populations are generally much harder to gather data on, and we would need to track them for a much longer period to notice if there had been any effect at all. Interventions focused on students who are just beginning their studies do not face these problems. Since we have identified a period in which a large (i.e., easily observable) number of women regularly stop studying philosophy, this means we have 
also identified a period where we can easily change certain variables and see if there is any effect. If this data is generalizable to institutions in other countries, attempts to show causal relationships between certain variables and women's representation do not necessarily need to rely upon lengthy trials. We can obtain good evidence by simply tracking what percentages of students take a second or third unit, which can often be done in under two years (with another two years to try to replicate the results).

Whether mending this initial undergraduate leak would result in gender gaps being reduced further down our discipline's pipeline seems like a promising avenue for future research, as there is currently very limited data. There is some prima facie evidence that closing undergraduate gender gaps could have significant effects on the gender gap at graduate school and faculty level. As noted in Section 4.1, women who began a master's or PhD in philosophy were not significantly less likely to complete their degree than men. This is consistent with Paxton et al. (2012) finding that the gender gap did not significantly increase for students in their study between majoring and graduate school, nor between graduate school and the faculty level. Additionally, Solomon and Clarke (2009) found that women were hired in proportion to the total number of PhD's granted to women. Jennings, Cobb, and Vinson (2015) found that men and women obtained academic positions within two years of graduation at similar rates, with women being more likely to secure a permanent academic placement. ${ }^{10}$ These combined findings suggest that alleviating the undergraduate gender gap could have substantial flow-on effects on gender gaps at higher levels in our discipline. Of course, this would only take place if most institutions closed their major-level gender gap, and only be noticeable after the extra women who choose to major had made their way through graduate school. However, some evidence counts against this possibility. As noted in Section 5, the UK has a much smaller undergraduate gender gap than the US and Australia but does not have significantly smaller graduate or faculty gender gaps.

\section{What Kinds of Early Interventions?}

Given Paxton et al. (2012) found that the proportion of students in introductory units who are female ranges roughly from $24-48 \%$ between institutions, it seems

10. Schwitzgebel \& Jennings (2016) find that women are less represented amongst higher levels of faculty, but it is not clear to what extent this is due to attrition and to what extent this is due to more women recently entering faculty positions. Ceci, Williams, \& Barnett find that there are fewer women as one moves up faculty ranks in many different fields, and attribute much of this to the "childbearing penalty" (2009: 250) women academics pay, particularly women who have children pre-tenure. 
unlikely that a one-size-fits-all approach will be effective. Different institutions are likely to have different rates of success with different interventions. One of the aims of this paper is to call for more willingness to simply try new interventions and see if they have any effects. Annually accessing enrolment statistics from faculty administration should make it relatively easy to track what proportion of female students go on to take a second philosophy unit and observe whether any attempted interventions are effective.

That being said, I believe some interventions are worth trying. Earlier I mentioned that much of the literature on philosophy's gender gaps has focused on identifying the causes of the gap, rather than assessing the efficacy of particular interventions. Whilst identifying causes allows us to make plausible inferences about which interventions could be effective, it is always possible that such inferences are mistaken. Identifying effective remedies is difficult, because the causal contribution of particular factors have not been assessed. It might be the case that the effect of a certain intervention is too small to be worthwhile, or is swamped by other factors, or that some interventions only have an effect on students who later leave philosophy for benign reasons. Because of such possibilities, I think it is important to look at studies which directly assess the efficacy of particular interventions.

Though few studies have assessed the efficacy of interventions on philosophy students, there is a very large literature examining the efficacy of interventions on reducing gender gaps in STEM fields. This could be instructive, given there are important similarities between philosophy and STEM fields (e.g., gendered stereotypes, a belief that innate 'brilliance' matters more than hard work-see Cheryan, Plaut, Handron, \& Hudson 2013; Hoh 2009; Leslie, Cimpian, Meyer, \& Freeland 2015). After reviewing this literature, I believe four kinds of early interventions are worth trying to reduce philosophy's gender gaps. ${ }^{11}$ These are:

11. Readers may be aware of some other interventions which purportedly cause dramatic reductions in racial and gender achievement gaps. Some recent studies raise questions about these interventions' validity, which is why I've refrained from endorsing them (though later research may vindicate them). I feel it is important to briefly cite these more recent studies, so readers are aware that the evidence is currently more mixed than is commonly presented, and any genuine effect sizes may be smaller than previously believed. For example, in 'values affirmation' interventions, students write a passage affirming values that are important to them. This purportedly causes minority students to achieve much higher grades, sometimes for years (Cohen, Garcia, Apfel, \& Master 2006; Sherman et al. 2013). Some studies report similarly positive results for female students in male-dominated fields (Kost-Smith et al. 2012; Miyake et al. 2010). Whilst these studies have received much media attention, and some support from philosophers (Schouten 2016; Thompson et al. 2016), there have been a number of failed replications (de Jong, Jellesma, Koomen, \& de Jong 2016; Dee 2015; Ege 2013; Hanselman, Rozek, Grigg, \& Borman 2017; Protzko \& Aronson 2016). These interventions, along with others, were sometimes thought to work by inoculating against stereotype threat. But as Thompson (2017) notes, some meta-analyses raise doubts about whether stereotype threat is a genuine phenomenon (Finnigan \& Corker 2016; Flore \& Wicherts 2015; Ganley et al. 2013; Stoet \& Geary 2012). This raises questions about whether other interven- 
exposing female students to role models, exposing female students to philosophy from an earlier age, boosting students' sense of belonging, and expanding the scope of jobs marketed towards philosophy students. ${ }^{12}$

\subsection{Role Model Interventions}

The first proposed intervention is having more women philosophers in roles where they can act as 'role models' for female students. Let me start by acknowledging that a number of large studies conclude that women's representation in a department's faculty has little to no effect on women's representation at the undergraduate and graduate level (Bettinger \& Long 2005; Canes \& Rosen 1995; Dynan \& Rouse 1997; Gilmartin, Denson, Li, Bryant, \& Aschbacher 2007; Hoffmann \& Oreopoulos 2009; Jensen \& Owen 2001; Neumark \& Gardecki 1996; Price 2010; Robb \& Robb 1999; Sonnert, Fox, \& Adkins 2007). Most of these studies' findings are inconsistent with a multitude of smaller scale interventions that report exposing female students to women in STEM roles has positive effects on students using a range of measures (see Olsson \& Martiny 2018 for a comprehensive summary). This makes it difficult to assess which studies are valid and reliable.

The problem with these larger studies is that they often amalgamate disciplines together, and treat all women instructors as having similar effects on female students (or lack thereof). The problem with the smaller studies is that many use high school students rather than college students, interventions are very short (e.g., reading one magazine article), success is often measured by student's self-reported interest shortly after said intervention, and researchers do not follow up on whether this interest was sustained over the long term or had an effect on choice of major (e.g., Cheryan, Meltzoff, \& Kim 2011; Lockwood 2006; Shin, Levy, \& London 2016). ${ }^{13}$ Readers aware of these studies may develop

tions thought to target stereotype threat are likely to be effective. Finally, interventions which teach students about 'growth mindset' purport to increase students' grades by changing students' beliefs that their aptitude is fixed and unlikely to be improved upon (Good, Rattan, \& Dweck 2012; Marra, Rodgers, Shen, \& Bogue 2009). Though popular, I am hesitant to support them due to some failed replications and worries about the statistical methods used in the most commonly cited studies (Li \& Bates 2017; Rienzo, Rolfe, \& Wilkinson 2015; Schwartz, Cheng, Salehi, \& Wieman 2016; Sisk, Burgoyne, Sun, Butler, \& Macnamara 2018). Some other interventions, such as 'task-value interventions', do have stronger evidence of efficacy. But they improve interest and test scores in men and women equally, which may make them ineffective for reducing gender gaps (see Harackiewicz \& Priniski 2018).

12. Note that unless specified otherwise, reported percentages in the remainder of this paper are absolute figures, e.g., an increase in the proportion of women majoring in a field from $10 \%$ to $20 \%$ is described as a $10 \%$ increase, not a $100 \%$ increase.

13. Many of these studies also claim to be assessing students' attitudes, confidence or beliefs by measuring students' implicit associations on the Implicit Association Test. The validity and reli- 
the impression that it is possible to cherry-pick results, or that there is too much contradictory evidence to form reasonable assessments. However, these inconsistent findings can be resolved. A number of rigorous studies avoid the methodological problems I've identified and appear able to explain why many larger studies conclude that increasing the number of female instructors has little effect on students' choice of major.

For example, Carrell, Page, and West (2010) looked at students in the US Air Force Academy randomly assigned to professors for a range of mandatory introductory courses. The authors found that when assigned male professors, female students scored $15 \%$ of a standard deviation lower than men whose math skills were comparable upon entry. Having a female professor reduced this gap by approximately two-thirds, and gains were even more pronounced for higherability female students. No gain was seen for students of female professors in history and English courses. In a follow-up study on students from the same academy, Mansour, Rees, Rintala, and Wozny (2018) replicated the original results and found that having more female professors substantially increased high-ability female students' chances of both completing a STEM master's degree and going into a STEM career.

Porter and Serra (2017) had a female 'role model' alumni visit economics classes to talk to students about their experiences as economics majors, and how majoring in economics helped them succeed in their careers. Role models were not told about the objectives of the study. The role models increased the chances that female students would take an intermediate microeconomics class the following year by $12 \%$, and the chances that female students would express the intention to major in economics by $7.8 \%$. The intervention had a particularly large effect on top female students, who saw a $26 \%$ increase in the likelihood of enrolling in the intermediate class. This dramatic result was partially attributable to the fact that the researchers chose alumni who were highly charismatic and had strong communication skills.

Kofoed (2019) took advantage of the random assignment of role models to cadets at another US military academy. He found that "when female cadets work with female officers, the probability that the female cadet selects her officer's occupational branch as her first choice or among her top three choices increases by 5.9 and 18.1 percentage points respectively" (2019: 2).

Dennehy and Dasgupta found that "women in engineering who were assigned a female (but not male) peer mentor experienced more belonging, motivation, and confidence in engineering, better retention in engineering majors, and greater engineering career aspirations" (2017: 5964).

ability of this test for assessing changes to a student's likelihood of majoring in a particular field is questionable (Blanton et al. 2009; Rezaei 2011). 
Asgari, Dasgupta, and Cote (2010) surveyed female engineering students at the beginning of their degrees and at the end of their sophomore year, asking about career goals, participation in class and implicit self-conceptions of leadership. It was found that students who had frequent and high-quality interactions with female engineering professors developed higher career goals and participated more in class, even after controlling for other factors. No benefit was observed for students who had frequent contact with female professors but did not perceive the professors to be particularly supportive.

These studies act as evidence that role models can increase the number of women majoring in philosophy and allow us to identify some plausible explanations for the earlier inconsistent results. A common theme in the studies is that the effect is field-specific, occurring only in fields stereotypically coded as male. A second theme from some studies, and the broader literature of role models, is that simply being a member of the same sex does not necessarily make one a role model in the relevant sense (although being of the same sex is a good way to improve one's chances of being seen as a role model). Students must identify with the instructors or perceive interactions with instructors to be of a certain quality (Lockwood \& Kunda 2000). ${ }^{14}$ Cheryan et al. (2011) notably found that

role model gender had no effect on success beliefs. However, women who interacted with non-stereotypical role models believed they would be more successful in computer science than those who interacted with stereotypical role models. Differences in women's success beliefs were mediated by their perceived dissimilarity from stereotypical role models. (2011: 656) ${ }^{15}$

\subsection{Social Belonging Interventions}

The second kind of intervention aims to improve students' sense of belonging. In two randomized and controlled interventions, Walton, Logel, Peach, Spencer, and Zanna (2015) successfully mitigated the effects of engineering's 'chilly climate'. Female engineering students were simply given the results of a survey of upper-level students' experiences, including audio recordings from participants. Some surveys emphasized that all students worried about their social belonging in the field at first, but that these concerns dissipated with time. This

14. Lockwood \& Kunda (2000) also argue role models' success must also be seen as attainable. For example, Betz and Sekaquaptewa (2012) actually found that middle school girls who disidentified with STEM careers were even less likely to want to study STEM subjects after being exposed to counter-stereotypical role models. This was seemingly due to viewing the role models as representing an unattainable standard.

15. Similar supporting evidence was also found by Cheryan, Drury, and Vichayapai (2013). 
“aimed to protect students' sense of belonging in engineering by providing a nonthreatening narrative with which to interpret instances of adversity" (2015: 468). Other recordings "emphasized that upper year students, both men and women, learned to incorporate broader aspects of their self-identity in their daily lives to manage stress and find 'balance' in engineering" (2015: 473). The interventions closed the gender gap in final grades, improved students' attitudes towards engineering, and led students to view daily adversities as much more manageable. However, they achieved these effects in different ways. The first group of surveys worked by substantially increasing female students' number of male engineer friends. The second caused female students to express broader aspects of their self-identity in engineering and develop external resources for support. Positive, though weaker, results have been obtained in very similar studies focused on racial gaps (Walton \& Cohen 2007; Yeager et al. 2016).

Social belonging may also be improved with letters from faculty. Herrmann et al. sent "a letter from a female role model who normalized concerns about belonging, presented time spent on academics as an investment, and exemplified overcoming challenges on academic performance and persistence" (2016:258) to students in psychology and chemistry courses. They found that the intervention improved grades ( $d=.24$ for psychology students, .66 for chemistry students), and also lead to lower rates of failing and withdrawing.

Letters of encouragement from faculty that don't target students' sense of belonging may still boost female students' motivation to remain in a field. $\mathrm{Li}$ (2018) sent female economics students whose grades were above the median information about career prospects, average earnings, and grade distributions, and an email encouraging them to major in economics. This increased the percentage of these students who went on to declare a major in economics one year later by $6 \%$, with even larger effects seen for students in their first year. ${ }^{16}$

Finally, some evidence that the presence of more women can have positive effects comes from Eisenkopf, Hessami, Fischbacher, and Ursprung (2015). They found that female high school students who were randomly assigned to all-female mathematics classes did better than those assigned to co-ed classes, having a $7-10 \%$ increase in their final math grades. These students also developed a stronger self-concept in mathematics and more positive self-assessment of their mathematics skills, with increases being particularly pronounced for high-ability students. ${ }^{17}$

16. Unfortunately it is not possible to tell from the study whether the increase was due to the letter or the information. Although there was a control group, the information package unexpectedly made both male and female students below the median less likely to declare economics as their major.

17. Interestingly, the authors found it was an absence of male students, rather than merely fewer male students, that led to increased scores. Females in co-ed classes with more males did not 


\subsection{Pre-Collegiate Interventions}

The third kind of intervention involves exposing girls to philosophy from a younger age. Schouten (2016) has argued that pre-collegiate philosophy programs could plausibly reduce philosophy's gender gaps in a number of ways, which I agree with. One is by reducing the chances of philosophy being stereotyped as male, and giving girls role models they could identify with. Another is by providing exercises which can inoculate girls against the effects of stereotypes or schemas, or improving their sense of belonging. Both of these effects seem prima facie plausible and are consistent with the literature I have discussed so far. Since most students do not have much exposure to philosophy before university, it also seems plausible that any impressions made on students by instructors are likely to last much longer than (say) the impressions that students might develop about scientists from attending a science camp.

Some studies suggest that early exposure to philosophy is also likely to reduce our discipline's gender gaps in another way. Whilst role models can plausibly prevent girls who are interested in an area of study from being dissuaded by stereotypes or a feeling that they wouldn't belong, early exposure gives students a greater opportunity to develop an interest in that area in the first place. ${ }^{18}$ For example, Legewie and DiPrete (2014) find that high schools with stronger math and science curricula have smaller gender gaps regarding students' plan to major in a STEM field at university, even after controlling for other variables such as dropout rate, teacher-student ratio, teacher salary, and the proportion of students who go to college. Federman (2007) finds that students from high schools in states that require completing more mathematics and science subjects to graduate had a higher likelihood of majoring in a STEM field, even after controlling for other factors. He estimates that requiring high school students to take an additional year of math and science would increase the proportion of female students who go on to major in STEM fields at college by $21 \%$, compared to only increasing the number of male students who go on to major in STEM fields at college by $13 \%$.

One of the most comprehensive surveys of the literature on the causes of gender gaps in STEM fields comes from Cheryan et al. (2017). Cheryan et al. argue that few hypotheses can successfully explain why STEM fields have a lower proportion of women than non-STEM fields and also explain the varia-

do significantly worse than females in co-ed classes with fewer males. The authors attribute these results to increased competitiveness between female students.

18. Cheryan, Ziegler, Montoya, \& Jiang (2017) note that many fields, such as psychology and nursing, do not have female gender gaps despite students lacking early experience with these fields. They argue a lack of early exposure only results in undergraduate gender gaps in fields where gendered stereotypes already exist. 
tion in women's representation between STEM sub-fields. However, students' early exposure to a field seems to correlate with which fields lack undergraduate gender gaps. ${ }^{19}$ It is notable that most US states require biology, chemistry, and mathematics (fields with small to no undergraduate gender gaps) to be taught in schools, whilst courses in computer science, engineering, and physics (fields with large undergraduate gender gaps) are usually optional and less likely to be offered (Macdonald, Zinth, \& Pompelia 2019; Nord et al. 2011). For example, in 2009 , only $19 \%$ of students had taken a computer science course, but $100 \%$ had taken at least one mathematics course (Department of Education, National Center for Education Statistics 2012). Statistics such as these lead Cheryan et al. to conclude that "having greater STEM course requirements may give girls opportunities to learn about a field instead of relying on stereotypes about what fields are like and how successful they would be in them" (2017: 15).

This is evidence that giving students experience with philosophy is likely to give many girls the chance to find out they enjoy philosophy before it comes time to consider college applications. Whilst detailing what such programs would look like and how they can be set up is outside the scope of this article, there are some instructive case studies (e.g., Grey 2008). For example, in many Australian elementary schools, time is allotted for weekly religious studies classes, but many students do not have particularly religious families or any desire to attend these classes. A program called Primary Ethics thus began setting up weekly ethics classes as an alternative, run by trained volunteers (Stuart 2014). The content of these classes goes beyond ethics, introducing questions regarding determinism, language and epistemology. Organizations such as the Federation of Australasian Philosophy in Schools Associations (FAPSA) also run school-wide philosophy days which supportive teachers can enlist whole classes into. ${ }^{20}$ FAPSA also helps train current teachers to integrate philosophical methodology into classes,

19. The other factors they identify are: negative stereotypes about what kinds of people enter those fields, negative stereotypes causing stereotype threat, a lack of role models, and gender gaps in self-efficacy. Having more role models for female students, boosting female students' selfefficacy, and giving students more early exposure to philosophy each seem likely to address these causes. Another comprehensive summary worth mentioning comes from Ceci et al. (2009). Ceci et al. argue that based on current evidence, the primary factors which explain why women are underrepresented in math-intensive fields include: women with high math ability preferring nonmath careers, women with high math ability having a wider range of careers open to them due to their having higher verbal competence relative to men, more men scoring in higher ranges on important gatekeeper tests, and women suffering a career penalty for having children. Cheryan et al. (2017) point out that Ceci. et al. don't examine the social and cultural factors which explain why women have different preferences to men or score lower on entry exams in the first place, and it is this question which Cheryan et. al try to answer.

20. An anonymous reviewer points out that pre-collegiate programs which are opt-in, such as camps or after-school classes, may attract a disproportionate number of boys. I agree, and am thus in favour of programs which can be integrated into existing educational structures, though these are admittedly more difficult to organise and implement. 
typically after convincing educators that pre-collegiate philosophy delivers tangible educational benefits to students (Fair et al. 2015; Gorard, Siddiqui, \& See 2015). There are numerous ways for teachers to have philosophically-themed lessons, such as by introducing students to conceptual analysis, hosting Communities of Inquiry, and exploring philosophical ideas through literature (Lipman 2010; McCall 2009; Wartenberg 2009). ${ }^{21}$

\subsection{Job Prospects}

Calhoun (2015) suggests one final kind of intervention which I believe is worth considering. She points to a large study from Pitt and Tepper (2012) demonstrating that job prospects is one of the primary determinants of university students' choice of major. ${ }^{22}$ By 'job prospects' Pitt and Tepper don't simply mean the probability of having stable employment or a high-paying job. Rather, what matters is the kinds of jobs that a degree can lead to. Calhoun notes that men and women often go into different kinds of careers (Corbett \& Hill 2012), and that when philosophers promote the benefits of majoring in philosophy they often emphasise the kinds of skills marketed towards male-dominated fields. For example, the first jobs listed in the APA's guidebook, 'A Non-Academic Career?' include business, consulting, computers and IT, and non-teaching education roles (American Philosophical Association 2002). Women may thus have "greater difficulty imagining how philosophy fits with the kinds of jobs they are most likely to occupy in a gender-structured workforce" (Calhoun 2015: 480) and this may lead to them choosing to major in other fields instead.

Calhoun argues we must keep in mind that

men and women fit into a gender-structured workforce in different ways, are socialized into and routinely confront different gendered expectations about what they will do and who they will be, and find themselves fitting or not fitting a different range of disciplinary stereotypes. (2015:483)

When we promote philosophy to students, we ought to emphasise how it can lead to the kinds of careers women are interested in. And when we are trying to change the stereotypes of what philosophy or philosophers are like, it may not

21. Other organisations which promote philosophy in schools, and can provide examples of what programs are possible, include the Philosophy Learning and Teaching Organization (PLATO), the International Council of Philosophical Inquiry with Children (ICPIC), the European Foundation for the Advancement of Doing Philosophy with Children (SOPHIA), and the UK Society for the Advancement of Philosophical Enquiry and Reflection in Education (SAPERE).

22. The other being whether the major expresses, or is connected to, one's identity, which is consistent with the aforementioned literature on role model effects and social belonging interventions. 
be enough to simply change the sex associated with philosophy, or conceptions of what philosophy majors are like. We should also change conceptions of what philosophy majors do.

Although it is intuitive enough that the careers a degree can lead to would have an effect on students' choices, one particular source of evidence for Calhoun's thesis is that men and women with the same degree often end up going into different careers or areas of specialisation. One salient example of this regards mathematics majors. Although it is common knowledge that STEM fields have large gender gaps like philosophy, many people may not know that mathematics is something of an outlier. In the US, women receive $18.7-19.7 \%$ of bachelor's degrees in engineering, physics, computing and IT, but $41-43 \%$ of bachelor's degrees in mathematics (Department of Education, National Center for Education Statistics 2017; Yslas Vélez, Maxwell, \& Rose 2014). Women also receive $46 \%$ of bachelor's degrees in mathematics across OECD countries (OECD 2012). The reason mathematics is included in lists of fields with large gender gaps is that it does have large gender gaps at the doctorate and faculty level. Women make up only $23 \%$ of U.S. mathematics faculty and receive only $28.5 \%$ of U.S. doctorates in mathematics (National Science Foundation, National Center for Science and Engineering Statistics 2014; Department of Education, National Center for Education Statistics 2017).

One might infer from this that mathematics doesn't have the factors which cause gender gaps in philosophy, physics and engineering. But this doesn't seem to be the case. Mathematics is a field which is stereotypically male, in which 'brilliance' is thought to be necessary to succeed, which has few female faculty to act as role models, and in which women experienced a reduced sense of belonging and identification compared to men (Cheryan, Plaut, et al. 2013; Good et al. 2012; Leslie et al. 2015).

Part of the explanation for why mathematics has a much smaller undergraduate gender gap seems to be it makes some in-demand careers more accessible that physics and computing do not, namely, mathematics teaching. In the UK, $26 \%$ of women with mathematics or computer science degrees go into teaching, compared to just $10 \%$ of men (Smith \& White 2018). In the US, approximately $20 \%$ of women aged 45 or younger with a mathematics degree report being in elementary or secondary, compared to only $9 \%$ of men (Ruggles et al. 2019). The gender gap between these figures is even higher for more contemporary graduates and seems to be increasing over time. Importantly, male and female mathematics students do not seem to develop these gendered career preferences only after arriving at university. According to the Cooperative Institutional Research Program American Freshman Surveys 2000-2008 (2008), 26.4\% of female students enrolling in mathematics degrees intended to go into teaching, compared to only $14.4 \%$ of male students. 
It is worth emphasising this is just one example. Female mathematics majors are much less likely to go into engineering or IT-related work than male mathematics majors, much more likely to go into health professions, and such gender gaps resemble differences in mathematics students' reported career intentions before they begin university. Men and women are also likely to go into different areas of specialisation within medicine, (Association of American Medical Colleges 2012), law (Bacik, Costello, \& Drew 2003), and economics (Chari \& Goldsmith-Pinkham 2017; Dolado, Felgueroso, \& Almunia 2012), and these differences don't seem entirely attributable to differences in workplace culture or environment.

Statistics such as these show we should be wary of assuming that university disciplines close to gender parity at the undergraduate level aren't affected by factors thought to create gender gaps. Instead, what can occur is that whilst (e.g.) stereotypes and schemas about careers affect students' motivations to study a particular field, their effect can be masked by other factors. Having particular careers open at the end of one's undergraduate degree may cause many female students to weather the effects these factors normally have. If the womendominated careers that a mathematics degree can lead to were no longer available, the number of women completing mathematics degrees would probably drop.

The upshot of all this is that Calhoun is correct: the kinds of careers students believe will be available to them at the end of a degree affects their choice of major. Thus one way of making majoring in philosophy more appealing to women is to highlight how it can lead to the kinds of jobs female students are likely to be considering after having over eighteen years of socialization and enculturation. Mathematics may be unlikely to reduce its gender gap further this way, since students already have much experience with the subject matter in their pre-collegiate schooling and have some idea of the kinds of careers a mathematics degree can lead to. But a silver lining to philosophy's absence from pre-collegiate schooling is that students are likely to have relatively weaker conceptions of what kinds of careers philosophy majors end up in, which are easier for us to change.

Another (albeit more challenging) option is to change the kinds of careers a philosophy major is in fact likely to lead to. This can be done by marketing the value of philosophy majors to industries with more women and having those fields in turn advertise their desire for people with philosophy degrees. Expanding the scope of careers we market as achievable with a philosophy degree could make students who are already interested in those careers more likely to consider majoring in philosophy. This may seem like the wrong kind of approach for trying to close graduate and faculty-level gender gaps, since most additional female students will intend to go into other careers. But as I argued in Section 
6, simply having more female students is likely to have flow-on benefits, which could reduce gender gaps at the graduate level. Mathematics does have lower graduate and faculty gender gaps than physics and engineering, and this is plausibly somewhat attributable to the greater proportion of women completing undergraduate degrees. Additionally, many professional philosophers began their undergraduate degrees intending to have a very different career but changed their mind as they took more philosophy units. Having a larger pool of women majoring in philosophy, even if they initially intend to end up somewhere else, can only add to the number of women who end up staying in our discipline.

\section{Conclusion}

This paper has identified a number of considerations important for understanding philosophy's gender gap. First, women are at a higher risk of leaving philosophy than men at every point throughout their undergraduate studies, and we now have a quantifiable measure of this relative risk at various points in time. Second, this relative risk appears to mostly occur during students' undergraduate studies, with women who commence research degrees being at similar relative risk of not completing these degrees as men. Third, there exists a large pool of women who take one philosophy unit but leave shortly after, and these women could be a potential resource in achieving gender parity. Fourth, measures which directly target this group of women need only a low rate of uptake in order to have a significant effect, in contrast to measures which focus on women who are closer to graduating. Fifth, trials aimed at identifying which factors improve women's representation could produce important data in a much shorter timespan than is typically assumed.

I have also considered the literature on interventions which aim to reduce gender gaps in STEM fields and identified a number of early interventions which could reduce philosophy's undergraduate gender gap. The first is to have more philosopher role models for students. Importantly, these role models must be seen as relatable, and support given to students needs to be of a certain quality. The second is to have interventions which boost women's sense of belonging. The third is to give more support to pre-collegiate philosophy programs, or initiatives which introduce philosophical methods into classes on other topics. The fourth is to expand the scope of careers we market to students as achievable with a philosophy degree.

When thinking of the gender gap, it is easy to concentrate on factors that seem most salient, and people who have recently left the discipline. But this risks focusing only on the people or factors one regularly encounters, or particular subgroups of women. If one doesn't have any involvement in first-year teach- 
ing, one never even encounters many of the women who make up a substantial proportion of the gender gap. One never meets many of the women who might have gone on to major in philosophy, but for certain factors.

Many departments are making laudable efforts to encourage female participation rates at various levels, but these have predominantly focused on the departmental and graduate level. These efforts should broaden in scope and pay more attention to reducing early undergraduate gender gaps. Waiting until students are in their third year or later risks waiting until many of philosophy's missing women have already left.

\section{Acknowledgements}

Thanks to Luke Russell, Dana Nelkin, Caroline West, Kristie Miller, Sam Shpall, Isabelle Wentworth, and two anonymous reviewers for helpful comments on earlier drafts. Thanks to Andrew Latham and Eric Schwitzgebel for statistical advice. Thanks to Zhengfeng Li at the Australian government's Department of Education for his continued patience and assistance with data access.

\section{References}

American Philosophical Association (2002). A Non-Academic Career? Retrieved from http://www.apaonline.org/?page=nonacademic\#illustrations

Antony, Louise (2012). Different Voices or Perfect Storm: Why Are There So Few Women in Philosophy? Journal of Social Philosophy, 43(3), 227-255. https://doi.org/10.1111/ j.1467-9833.2012.01567.x

Asgari, Shaki, Nilanjana Dasgupta, and Nicole G. Cote (2010). When Does Contact with Successful Ingroup Members Change Self-Stereotypes? Social Psychology, 41(3), 203211. https://doi.org/10.1027/1864-9335/a0ooo28

Association of American Medical Colleges (2012). 2012 Physician Specialty Data Book. Retrieved from Center for Workforce Studies: https://www.aamc.org/download/313228/data/2012physicianspecialtydatabook.pdf

Australian Government (2015). Selected Higher Education Statistics - 2015 Student Data. Retrieved from https://docs.education.gov.au/node/41696

Bacik, Ivana, Cathryn Costello, and Eileen P. Drew (2003). Gender InJustice: Feminising the Legal Professions? Trinity College Dublin Law School.

Beebee, Helen and Jennifer Saul (2011). Women in Philosophy in the UK: A Report by the British Philosophical Association and the Society for Women in Philosophy UK. Joint BPA/ SWIP Committee for Women in Philosophy. Retrieved from http://www.bpa.ac.uk/ uploads/2011/o2/BPA_Report_Women_In_Philosophy.pdf

Bettinger, Eric P. and Bridget T. Long (2005). Do Faculty Serve as Role Models? The Impact of Instructor Gender on Female Students. American Economic Review, 95(2), 152-157. https://doi.org/10.1257/000282805774670149 
Betz, Diana E. and Denise Sekaquaptewa (2012). My Fair Physicist? Feminine Math and Science Role Models Demotivate Young Girls. Social Psychological and Personality Science, 3(6), 738-746. https://doi.org/10.1177/1948550612440735

Blanton, Hart, James Jaccard, Jonathan Klick, Barbara Mellers, Gregory Mitchell, and Philip E. Tetlock (2009). Strong Claims and Weak Evidence: Reassessing the Predictive Validity of the IAT. Journal of Applied Psychology, 94(3), 567-582. https://doi. org/10.1037/ao014665

Calhoun, Cheshire (2009). The Undergraduate Pipeline Problem. Hypatia, 24(2), 216-223. https://doi.org/10.1111/j.1527-2001.2009.01040.x

Calhoun, Cheshire (2015). Precluded Interests. Hypatia, 30(2), 475-485. https://doi. org/10.1111/hypa.12149

Canes, Brandice J. and Harvey S. Rosen (1995). Following in Her Footsteps? Faculty Gender Composition and Women's Choices of College Majors. Industrial and Labor Relations Review, 48(3), 486-504. https://doi.org/10.1177/001979399504800308

Carrell, Scott E., Marianne E. Page, and James E. West (2010). Sex and Science: How Professor Gender Perpetuates the Gender Gap. The Quarterly Journal of Economics, 125(3), 1101-1144. https://doi.org/10.1162/qjec.2010.125·3.1101

Ceci, Stephen J., Wendy M. Williams, and Susan M. Barnett (2009). Women's Underrepresentation in Science: Sociocultural and Biological Considerations. Psychological Bulletin, 135(2), 218-261. https://doi.org/10.1037/a0014412

Chari, Anusha and Paul Goldsmith-Pinkham (2017). Gender Representation in Economics across Topics and Time: Evidence from the NBER Summer Institute. National Bureau of Economic Research. Retrieved from https://www.nber.org/papers/w23953. https:// doi.org/10.3386/w23953

Cheryan, Sapna, Benjamin J. Drury, and Marissa Vichayapai (2013). Enduring Influence of Stereotypical Computer Science Role Models on Women's Academic Aspirations. Psychology of Women Quarterly, 37(1), 72-79. https://doi.org/10.1177/0361684312459328

Cheryan, Sapna, Andrew N. Meltzoff, and Saenam Kim (2011). Classrooms Matter: The Design of Virtual Classrooms Influences Gender Disparities in Computer Science Classes. Computers \& Education, 57(2), 1825-1835. https://doi.org/10.1016/j.compedu.2011.02.004

Cheryan, Sapna, Victoria C. Plaut, Caitlin Handron, and Lauren Hudson (2013). The Stereotypical Computer Scientist: Gendered Media Representations as a Barrier to Inclusion for Women. Sex Roles, 69(1-2), 58-71. https://doi.org/10.1007/s11199-0130296-x

Cheryan, Sapna, Sianna A. Ziegler, Amanda K. Montoya, and Lily Jiang (2017). Why Are Some STEM Fields More Gender Balanced than Others? Psychological Bulletin, 143(1), 1-35. https://doi.org/10.1037/bulooooo52

Cohen, Geoffrey L., Julio Garcia, Nancy Apfel, and Allison Master (2006). Reducing the Racial Achievement Gap: A Social-Psychological Intervention. Science, 313(5791), 1307-1310. https://doi.org/10.1126/science.1128317

Cooperative Institutional Research Program (2008). American Freshman Survey 2000-2008. Retrieved from https://heri.gseis.ucla.edu/archives

Corbett, Christianne and Catherine Hill (2012). Graduating to a Pay Gap: The Earnings of Women and Men One Year after College Graduation. Retrieved from https://www.aauw. org/research/graduating-to-a-pay-gap/

de Jong, Elisabeth M., Francine C. Jellesma, Helma M. Y. Koomen, and Peter F. de Jong 
(2016). A Values-Affirmation Intervention Does Not Benefit Negatively Stereotyped Immigrant Students in the Netherlands. Frontiers in Psychology, 7(691), 1-20. https:// doi.org/10.3389/fpsyg.2016.00691

Dee, Thomas S. (2015). Social Identity and Achievement Gaps: Evidence from an Affirmation Intervention. Journal of Research on Educational Effectiveness, 8(2), 149-168. https://doi.org/10.1080/19345747.2014.906009

Dennehy, Tara C. and Nilanjana Dasgupta (2017). Female Peer Mentors Early in College Increase Women's Positive Academic Experiences and Retention in Engineering. Proceedings of the National Academy of Sciences, 114(23), 5964-5969. https://doi. org/10.1073/pnas.1613117114

Department of Education, National Center for Education Statistics (2012). Percentage of Public and Private High School Graduates Taking Selected Mathematics and Science Courses in High School, by Sex and Race/Ethnicity: Selected Years, 1982 through 2009. Retrieved from https://nces.ed.gov/programs/digest/d17/tables/dt17_225.30.asp

Department of Education, National Center for Education Statistics (2017). Table 318.30. Bachelor's, Master's, and Doctor's Degrees Conferred by Postsecondary Institutions, by Sex of Student and Discipline Division: 2015-16. Retrieved from: https://nces.ed.gov/programs/digest/d17/tables/dt17_318.30.asp

Dobbs, Chris (2017). Evidence Supporting Pre-University Effects Hypotheses of Women's Underrepresentation in Philosophy. Hypatia, 32(4), 940-945. https://doi.org/10.1111/ hypa. 12356

Dodds, Susan and Eliza Goddard (2013). Not Just a Pipeline Problem. In Katrina Hutchison and Fiona Jenkins (Eds.), Women in Philosophy: What Needs to Change? (143-161). Oxford University Press. https://doi.org/10.1093/acprof:0so/9780199325603.003.0008

Dolado, Juan J., Florentino Felgueroso, and Miguel Almunia (2012). Are Men and Women-Economists Evenly Distributed across Research Fields? Some New Empirical Evidence. SERIES, 3(3), 367-393. https://doi.org/10.1007/s13209-011-0065-4

Dougherty, Tom, Samuel Baron, and Kristie Miller (2015a). Female Under-Representation among Philosophy Majors: A Map of the Hypotheses and a Survey of the Evidence. Feminist Philosophy Quarterly, I(1), 1-20. https://doi.org/10.5206/fpq/2015.1.4

Dougherty, Tom, Samuel Baron, and Kristie Miller (2015b). Why Do Female Students Leave Philosophy? The Story from Sydney. Hypatia, 3o(2), 467-474. https://doi. org/10.1111/hypa.12150

Dynan, Karen E. and Cecilia E. Rouse (1997). The Underrepresentation of Women in Economics: A Study of Undergraduate Economics Students. The Journal of Economic Education, 28(4), 350-368. https://doi.org/10.1080/00220489709597939

Ege, Engin (2013). A Social Belonging Intervention for Minority Students (Master's thesis). University of Florida. Retrieved from https://ufdc.ufl.edu/UFEoo45868/oooo1. https://doi.org/10.1037/e567672014-001

Eisenkopf, Gerald, Zohal Hessami, Urs Fischbacher, and Heinrich Ursprung (2015). Academic Performance and Single-Sex Schooling: Evidence from a Natural Experiment in Switzerland. Journal of Economic Behavior \& Organization, 115, 123-143. https://doi. org/10.1016/j.jebo.2014.08.004

Fair, Frank, Lory E. Haas, Carol Gardosik, Daphne D. Johnson, Debra P. Price, and Olena Leipnik (2015). Socrates in the Schools from Scotland to Texas: Replicating a Study on the Effects of a Philosophy for Children Program. Journal of Philosophy in Schools, 2(1), 18-37. https://doi.org/10.21913/JPS.v2i1.1100 
Federman, Maya (2007). State Graduation Requirements, High School Course Taking, and Choosing a Technical College Major. The B.E. Journal of Economic Analysis and Policy, 7(1), Article 4. https://doi.org/10.2202/1935-1682.1521

Finnigan, Katherine M. and Katherine S. Corker (2016). Do Performance Avoidance Goals Moderate the Effect of Different Types of Stereotype Threat on Women's Math Performance? Journal of Research in Personality, 63, 36-43. https://doi.org/10.1016/j. jrp.2016.05.009

Flore, Paulette C. and Jelte M. Wicherts (2015). Does Stereotype Threat Influence Performance of Girls in Stereotyped Domains? A Meta-Analysis. Journal of School Psychology, 53(1), 25-44. https://doi.org/10.1016/j.jsp.2014.10.002

Friedman, Marilyn (2013). Why Should We Care? In Katrina Hutchison and Fiona Jenkins (Eds.), Women in Philosophy: What Needs to Change? (21-36). Oxford University Press.

Ganley, Colleen M., Leigh A. Mingle, Allison M. Ryan, Katherine Ryan, Marina Vasilyeva, and Michelle Perry (2013). An Examination of Stereotype Threat Effects on Girls' Mathematics Performance. Developmental Psychology, 49(10), 1886-1897. https://doi. org/10.1037/ao031412

Gilmartin, Shannon, Nida Denson, Erika Li, Alyssa Bryant, and Pamela Aschbacher (2007). Gender Ratios in High School Science Departments: The Effect of Percent Female Faculty on Multiple Dimensions of Students' Science Identities. Journal of Research in Science Teaching, 44(7), 980-1009. https://doi.org/10.1002/tea.20179

Goddard, Eliza, Susan Dodds, Lynda Burns, Mark Colyvan, Frank Jackson, and Karen Jones (2008). Improving the Participation of Women in the Philosophy Profession Report C: Students by Gender in Philosophy Programs in Australian Universities. Report to the Australasian Association of Philosophy, compiled by E. Goddard on behalf of the Committee of Senior Academics Addressing the Status of Women in the Philosophy Profession. Retrieved from https://aap.org.au/Resources/Documents/publications/ IPWPP/IPWPP_ReportC_Students.pdf

Good, Catherine, Aneeta Rattan, and Carol S. Dweck (2012). Why Do Women Opt Out? Sense of Belonging and Women's Representation in Mathematics. Journal of Personality and Social Psychology, 102(4), 700-717. https://doi.org/10.1037/ao026659

Gorard, Stephen, Nadia Siddiqui, and Beng H. See (2015). Philosophy for Children: Evaluation Report and Executive Summary. Education Endowment Foundation. Retrieved from https://eric.ed.gov/?id=ED581147

Grey, Steve (2008, 6 September). From Playdough to Plato. Brisbane Times. Retrieved from https:/www.brisbanetimes.com.au/lifestyle/from-playdough-to-plato-200809o6-geabnl.html

Hanselman, Paul, Christopher S. Rozek, Jeffrey Grigg, and Geoffrey D. Borman (2017). New Evidence on Self-Affirmation Effects and Theorized Sources of Heterogeneity from Large-Scale Replications. Journal of Educational Psychology, 109(3), 405-424. https://doi.org/10.1037/eduoooo141

Harackiewicz, Judith M. and Stacy J. Priniski (2018). Improving Student Outcomes in Higher Education: The Science of Targeted Intervention. Annual Review of Psychology, 69, 409-435. https://doi.org/10.1146/annurev-psych-122216-011725

Haslanger, Sally (2008). Changing the Ideology and Culture of Philosophy: Not by Reason (Alone). Hypatia, 23(2), 210-223. https://doi.org/10.1111/j.1527-2001.2008. tbo1195.x 
Herrmann, Sarah D., Robert Mark Adelman, Jessica E. Bodford, Oliver Graudejus, Morris A. Okun, and Virginia S. Y. Kwan (2016). The Effects of a Female Role Model on Academic Performance and Persistence of Women in STEM Courses. Basic and Applied Social Psychology, 38(5), 258-268. https://doi.org/10.1080/o1973533.2016.1209757

Hoffmann, Florian and Philip Oreopoulos (2009). A Professor Like Me: The Influence of Instructor Gender on College Achievement. The Journal of Human Resources, 44(2), 479-494. https://doi.org/10.3368/jhr.44.2.479

Hoh, Yin Kiong (2009). Using Notable Women in Environmental Engineering to Dispel Misperceptions of Engineers. International Journal of Environmental Science Education, 4(2), 117-131.

Jennings, Carolyn Dicey, Patrice Cobb, and David W. Vinson (2016, May 3). Academic Placement Data and Analysis: An Update with a Focus on Gender [Blog post]. Blog of the APA. Retrieved from https://blog.apaonline.org/2016/05/03/academic-placementdata-and-analysis-an-update-with-a-focus-on-gender/

Jensen, Elizabeth J. and Ann L. Owen (2001). Pedagogy, Gender, and Interest in Economics. The Journal of Economic Education, 32(4), 323-343. https://doi. org/10.1080/00220480109596112

Kofoed, Michael S. (2019). The Effect of Same-Gender or Same-Race Role Models on Occupation Choice Evidence from Randomly Assigned Mentors at West Point. Journal of Human Resources, 54(2), 430-467. https://doi.org/10.3368/jhr.54.2.0416.7838R1

Kost-Smith, Lauren E., Steven J. Pollock, Noah D. Finkelstein, Geoffrey L. Cohen, Tiffany A. Ito, and Akira Miyake (2012). Replicating a Self-Affirmation Intervention to Address Gender Differences: Successes and Challenges. AIP Conference Proceedings, 1413(1), 231-234. https://doi.org/10.1063/1.3680037

Legewie, Joscha and Thomas A. DiPrete (2014). The High School Environment and the Gender Gap in Science and Engineering. Sociology of Education, 87(4), 259-280. https://doi.org/10.1177/0038040714547770

Leslie, Sarah-Jane, Andrei Cimpian, Meredith Meyer, and Edward Freeland (2015). Expectations of Brilliance Underlie Gender Distributions across Academic Disciplines. Science, 347(6219), 262-265. https://doi.org/10.1126/science.1261375

Li, Hsueh-Hsiang (2018). Do Mentoring, Information, and Nudge Reduce the Gender Gap in Economics Majors? Economics of Education Review, 64, 165-183. https://doi. org/10.1016/j.econedurev.2018.04.004

Li, Yu and Timothy Bates (2017). Does Growth Mindset Improve Children's IQ, Educational Attainment or Response to Setbacks? Active-Control Interventions and Data on Children's Own Mindsets. Unpublished manuscript. Retrieved from https://osf.io/tsdwy/. https:/doi.org/10.31235/osf.io/tsdwy

Lipman, Matthew (2010). Philosophy Goes to School. Temple University Press.

Lockwood, Penelope (2006). "Someone Like Me Can Be Successful": Do College Students Need Same-Gender Role Models? Psychology of Women Quarterly, 30(1), 36-46. https://doi.org/10.1111/j.1471-6402.2006.00260.x

Lockwood, Penelope and Ziva Kunda (2000). Outstanding Role Models: Do They Inspire or Demoralize Us? In Abraham Tesser, Richard B. Felson, and Jerry M. Suls (Eds.), Psychological Perspectives on Self and Identity (147-171). American Psychological Association. https://doi.org/10.1037/10357-006

Macdonald, Heidi, Jennifer Dounay Zinth, and Sarah Pompelia (2019). 50-State Comparison: High School Graduation Requirements. Retrieved from Education Commission of the States website: https://www.ecs.org/high-school-graduation-requirements/ 
Mackenzie, Catriona and Cynthia Townley (2013). Women In and Out of Philosophy. In Katrina Hutchison and Fiona Jenkins (Eds.), Women in Philosophy: What Needs to Change? (164). Oxford University Press. https://doi.org/10.1093/acprof:o so/9780199325603.003.0009

Mansour, Hani, Daniel I. Rees, Bryson Rintala, and Nathan Wozny (2018). The Effects of Professor Gender on the Post-Graduation Outcomes of Female Students. IZA Discussion Papers 11820. Institute of Labor Economics.

Marra, Rose M., Kelly A. Rodgers, Demei Shen, and Barbara Bogue (2009). Women Engineering Students and Self-Efficacy: A Multi-Year, Multi-Institution Study of Women Engineering Student Self-Efficacy. Journal of Engineering Education, 98(1), 27-38. https://doi.org/10.1002/j.2168-9830.2009.tbo1003.x

McCall, Catherine C. (2009). Transforming Thinking: Philosophical Inquiry in the Primary and Secondary Classroom. Routledge.

Miyake, Akira, Lauren E. Kost-Smith, Noah D. Finkelstein, Steven J. Pollock, Geoffrey L. Cohen, and Tiffany A. Ito (2010). Reducing the Gender Achievement Gap in College Science: A Classroom Study of Values Affirmation. Science, 330(6008), 1234-1237. https://doi.org/10.1126/science.1195996

National Science Foundation, National Center for Science and Engineering Statistics (2014). Table 17. Employed Doctoral Scientists and Engineers in 4-Year Educational Institutions, by Broad Field of Doctorate, Sex, and Faculty Rank: 2013. Retrieved from https:// ncsesdata.nsf.gov/doctoratework/2013/html/SDR2013_DST17.html

National Science Foundation, National Center for Science and Engineering Statistics, Directorate For Social, Behavioral And Economic Sciences (2017). 2015 Doctorate Recipients From U.S. Universities (NSF 17-306). Retrieved from https://www.nsf.gov/statistics/2017/nsf17306/static/report/nsf17306.pdf

Neumark, David and Rosella Gardecki (1996). Women Helping Women? Role-Model and Mentoring Effects on Female Ph.D. Students in Economics. Journal of Economic Resources, 33(1), 220-246. https://doi.org/10.2307/146320

Nord, Christine, Shep Roey, Robert Perkins, Marsha Lyons, Nita Lemanski, Janis Brown, and Jason Schuknecht (2011). The Nation's Report Card: America's High School Graduates (NCES 2011-462). Retrieved from US Department of Education, National Center for Education Statistics: https://nces.ed.gov/nationsreportcard/pdf/studies/2011462. pdf

Norlock, Kathryn (2006). Women in the Profession: A More Formal Report to the CSW. American Philosophical Association Committee on the Status of Women. Retrieved from https://bit.ly/376jGJT

Norlock, Kathryn (2011). Update on Women in the Profession. Retrieved from http://www. apaonlinecsw.org/data-on-women-in-philosophy

OECD (2012). Table A4.6. Percentage of Qualifications Awarded to Women in TertiaryType A and Advanced Research Programmes, by Field of Education (2000, 2010). Education at a Glance 2012. Retrieved from https://www.phil-fak.uni-duesseldorf.de/ fileadmin/Redaktion/Institute/Sozialwissenschaften/BF/Barz/Aktuelles/EAG_2012_ Indicators.pdf

Olsson, Maria I. T. and Sarah E. Martiny (2018). Does Exposure to Counterstereotypical Role Models Influence Girls' and Women's Gender Stereotypes and Career Choices? A Review of Social Psychological Research. Frontiers in Psychology, 9, Article 2264. https://doi.org/10.3389/fpsyg.2018.02264 
Paxton, Molly (2013). 2012/2013 Pacific Division Conference Participation Data Report. American Philosophical Association. Retrieved from https://cdn.ymaws.com/www. apaonline.org/resource/group/bf785bod-eb59-41f8-9436-1c9c26f5of8e/demographic. paxton.2013.pdf

Paxton, Molly, Carrie Figdor, and Valerie Tiberius (2012). Quantifying the Gender Gap: An Empirical Study of the Underrepresentation of Women in Philosophy. Hypatia, 27(4), 949-957. https://doi.org/10.1111/j.1527-2001.2012.01306.x

Pitt, Richard N. and Steven A. Tepper (2012). Double Majors: Influences, Identities, and Impacts. The Teagle Foundation, Curb Center, Vanderbilt University. Retrieved from https://www.researchgate.net/publication/279985369_Double_Majors_Influences_ Identities_and_Impacts

Porter, Catherine and Danila Serra (2017). Gender Differences in the Choice of Major: The Importance of Female Role Models. Southern Methodist University Economics Working Paper 1705. Retrieved from: https://ideas.repec.org/p/smu/ecowpa/1705.html

Price, Joshua (2010). The Effect of Instructor Race and Gender on Student Persistence in STEM Fields. Economics of Education Review, 29(6), 901-910. https://doi.org/10.1016/j. econedurev.2010.07.009

Protzko, John and Joshua Aronson (2016). Context Moderates Affirmation Effects on the Ethnic Achievement Gap. Social Psychological and Personality Science, 7(6), 500-507. https://doi.org/10.1177/1948550616646426

Rezaei, Ali R. (2011). Validity and Reliability of the IAT: Measuring Gender and Ethnic Stereotypes. Computers in Human Behavior, 27(5), 1937-1941. https://doi.org/10.1016/j. chb.2011.04.018

Rienzo, Cinzia, Heather Rolfe, and David Wilkinson (2015). Changing Mindsets: Evaluation Report and Executive Summary. Education Endowment Foundation. Retrieved from https://eric.ed.gov/?id=ED581132

Robb, Roberta E. and Leslie Robb (1999). Gender and the Study of Economics: The Role of Gender of the Instructor. The Journal of Economic Education, 30(1), 3-19. https://doi. org/10.1080/00220489909595933

Ruggles, Steven, Sarah Flood, Ronald Goeken, Josiah Grover, Erin Meyer, Jose Pacas, and Matthew Sobek (2019). Integrated Public Use Microdata Series USA: Version 9.0 [American Community Survey Microdata Series 1 Year Estimates for 2014, 2015, 2016] (Publication no. 10.18128/Do10.V9.0). Retrieved from https://usa.ipums.org/ usa/index.shtml

Schouten, Gina (2016). Philosophy in Schools: Can Early Exposure Help Solve Philosophy's Gender Problem? Hypatia, 31(2), 275-292. https://doi.org/10.1111/hypa.12232

Schwartz, Daniel L., Katherine M. Cheng, Shima Salehi, and Carl Wieman (2016). The Half Empty Question for Socio-Cognitive Interventions. Journal of Educational Psychology, 108(3), 397-404. https://doi.org/10.1037/eduoooo122

Schwitzgebel, Eric (2016). Percentages of US Doctorates in Philosophy Given to Women and to Minorities, 1973-2014 [Blog post]. Retrieved from http://schwitzsplinters.blogspot. com.au/2016/o1/percentages-of-us-doctorates-in.html

Schwitzgebel, Eric and Carolyn Dicey Jennings (2016). Women in Philosophy: Quantitative Analyses of Specialization, Prevalence, Visibility, and Generational Change. Public Affairs Quarterly, 31(2), 83-105.

Sherman, David K., Kimberly A. Hartson, Kevin R. Binning, Valerie Purdie-Vaughns, Julio Garcia, Suzanne Taborsky-Barba, Sarah Tomassetti, David Nussbaum, and 
Geoffrey L. Cohen (2013). Deflecting the Trajectory and Changing the Narrative: How Self-Affirmation Affects Academic Performance and Motivation Under Identity Threat. Journal of Personality and Social Psychology, 104(4), 591-618. https://doi. org/10.1037/ao031495

Shin, Jiyun Elizabeth L., Sheri R. Levy, and Bonita London (2016). Effects of Role Model Exposure on STEM and Non-STEM Student Engagement. Journal of Applied Social Psychology, 46(7), 410-427. https://doi.org/10.1111/jasp.12371

Sisk, Victoria F., Alexander P. Burgoyne, Jingze Sun, Jennifer L. Butler, and Brooke N. Macnamara (2018). To What Extent and Under Which Circumstances Are Growth Mind-Sets Important to Academic Achievement? Two Meta-Analyses. Psychological Science, 29(4), 549-571. https://doi.org/10.1177/0956797617739704

Smith, Emma and Patrick White (2018). The Employment Trajectories of Science, Technology, Engineering and Mathematics Graduates. The Nuffield Foundation. Retrieved from https://www2.le.ac.uk/departments/sociology/people/pwhite/TheemploymenttrajectoriesofSTEMgraduatesFINALREPORT20180801.pdf. https:/doi. org/10.29311/2019.04

Solomon, Miriam and John Clarke (2009). CSW “Jobs for Philosophers" Employment Study. Proceedings and Addresses of The American Philosophical Association, 82(5), 189195.

Sonnert, Gerhard, Mary F. Fox, and Kristen Adkins (2007). Undergraduate Women in Science and Engineering: Effects of Faculty, Fields, and Institutions over Time. Social Science Quarterly, 88(5), 1333-1356. https://doi.org/10.1111/j.1540-6237.2007.00505.x

Stoet, Gijsbert and David C. Geary (2012). Can Stereotype Threat Explain the Gender Gap in Mathematics Performance and Achievement? Review of General Psychology, 16(1), 93-102. https://doi.org/10.1037/aoo26617

Stuart, John (2014, 16 July). Ethics Classes Rolled Out to Kindergarten Students in New South Wales Public Schools. The Australian Broadcasting Corporation. Retrieved from https://www.abc.net.au/news/2014-07-16/ethics-classes-rolled-out-in-nsw-kindergartens/5603066

Thompson, Morgan (2017). Explanations of the Gender Gap in Philosophy. Philosophy Compass, 12(3), e12406. https://doi.org/10.1111/phc3.12406

Thompson, Morgan, Toni Adleberg, Sam Sims, and Eddy Nahmias (2016). Why Do Women Leave Philosophy? Surveying Students at the Introductory Level. Philosophers' Imprint, 16(6), 1-36.

UK Higher Education Statistics Authority (2017). HE Student Enrolments by Level of Study, Subject Area, Mode of Study and Sex 2011/12 to 2015/16 (Table 4). Retrieved from https:// www.hesa.ac.uk/file/6436/download?token=Sy_PoqYn

Valian, Virginia (2005). Beyond Gender Schemas: Improving the Advancement of Women in Academia. Hypatia, 20(3), 198-213. https://doi.org/10.1111/j.1527-2001.2005. tboo495.x

Van Camp, Julie (2010). Tenured/Tenure-Track Faculty Women at 98 US Doctoral Programs in Philosophy. Retrieved from https://web.csulb.edu/ jvancamp/doctoral_2004.html

Walton, Gregory M. and Geoffrey L. Cohen (2007). A Question of Belonging: Race, Social Fit, and Achievement. Journal of Personality and Social Psychology, 92(1), 82-96. https:// doi.org/10.1037/0022-3514.92.1.82

Walton, Gregory M., Christine Logel, Jennifer M. Peach, Steven J. Spencer, and Mark P. Zanna (2015). Two Brief Interventions to Mitigate a "Chilly Climate" Transform 
Women's Experience, Relationships, and Achievement in Engineering. Journal of Educational Psychology, 107(2), 468-485. https://doi.org/10.1037/aoo37461

Wartenberg, Thomas E. (2009). Big Ideas for Little Kids: Teaching Philosophy Through Children's Literature. R\&L Education.

Weinberg, Justin (2018). Demographic Diversity Is Good for Philosophy [Blog post]. Retrieved from http://dailynous.com/2018/10/26/demographic-diversity-good-philosophy/

Wilhelm, Isaac, Sherri Lynn Conklin, and Nicole Hassoun (2017). New Data on the Representation of Women in Philosophy Journals: 2004-2015. Philosophical Studies, 175(6), 1441-1464. https://doi.org/10.1007/s11098-017-0919-0

Yeager, David S., Gregory M. Walton, Shannon T. Brady, Ezgi N. Akcinar, David Paunesku, Laura Keane, Donald Kamentz, Gretchen Ritter, Angela Lee Duckworth, and Robert Urstein (2016). Teaching a Lay Theory before College Narrows Achievement Gaps at Scale. Proceedings of the National Academy of Sciences, 113(24), E3341-E3348. https://doi.org/10.1073/pnas.1524360113

Yslas Vélez, William, James W. Maxwell, and Colleen A. Rose (2014). Fall 2013 Departmental Profile Report. Retrieved from The American Mathematical Society website: http://www.ams.org/profession/data/annual-survey/2013Survey-DepartmentalProfile-Report.pdf 